\title{
Uniportal video-assisted thoracic surgery or single-incision video-assisted thoracic surgery for lung resection: clarifying definitions
}

\author{
“...we have attempted to resolve the existing ambiguity in \\ video-assisted thoracic surgery procedures, and propose specific terms \\ identifying distinct approaches for minimally invasive thoracic \\ procedures."
}

Marcello Migliore ${ }^{*, 1}$, Semih Halezeroglu ${ }^{2}$, Laureano Molins ${ }^{3}$, Dirk Van Raemdonck ${ }^{4}$, Michael R Mueller ${ }^{5}$, Federico Rea ${ }^{6} \&$ Subroto Paul ${ }^{7}$

First draft submitted: 3 August 2016; Accepted for publication: 8 September 2016; Published online: 7 October 2016

The field of minimally invasive thoracic surgery is relatively new, and recently there has been evidence of modifications to video-assisted thoracic surgery (VATS) approaches from groups around the world. VATS is becoming a vague term, as at this point in time it is too ambiguous, and there are several definitions of recent variations in the technique used to perform lung resection that are not well understood. These include uniportal (single-port) VATS and single-incision VATS [1]. The question arises whether all these terms are correctly used to indicate the same mini-invasive technique. An example of ambiguity in terms is that many surgeons may perform 'uniportal' VATS for lung resection through a $6-\mathrm{cm}$ single skin incision which some authors consider a minithoracotomy [2] .

As a universally accepted definition is important for surgical practice worldwide, an attempt to clarify VATS terminology was published in 2000 [3] but the confusion has not been clarified yet, with attempts to provide a definition seemingly more complicated now than before. The key concern is precisely outlining what we are talking about when we mention uniportal VATS, this term has been used since its inception for relatively minor operations [4-7].

The problem emerging now correlates with the introduction of uniportal VATS lobectomy [8]. Though many surgeons perform pneumonectomy with this technique; how should we define it? As a uniportal VATS pneumonectomy? It is difficult to image how lung may be removed from a small port. One of the problems may be, that the word 'port' indicates "a small entrance, especially with a 'trocar'." However, completing a lobectomy and

\section{KEYWORDS}

- anatomical VATS resection - low volume center $\bullet \mathrm{NSCLC} \bullet$ VATS lobectomy

"The field of minimally invasive thoracic surgery is relatively new, and recently there has been evidence of modifications to video-assisted thoracic surgery approaches from groups around the world." 


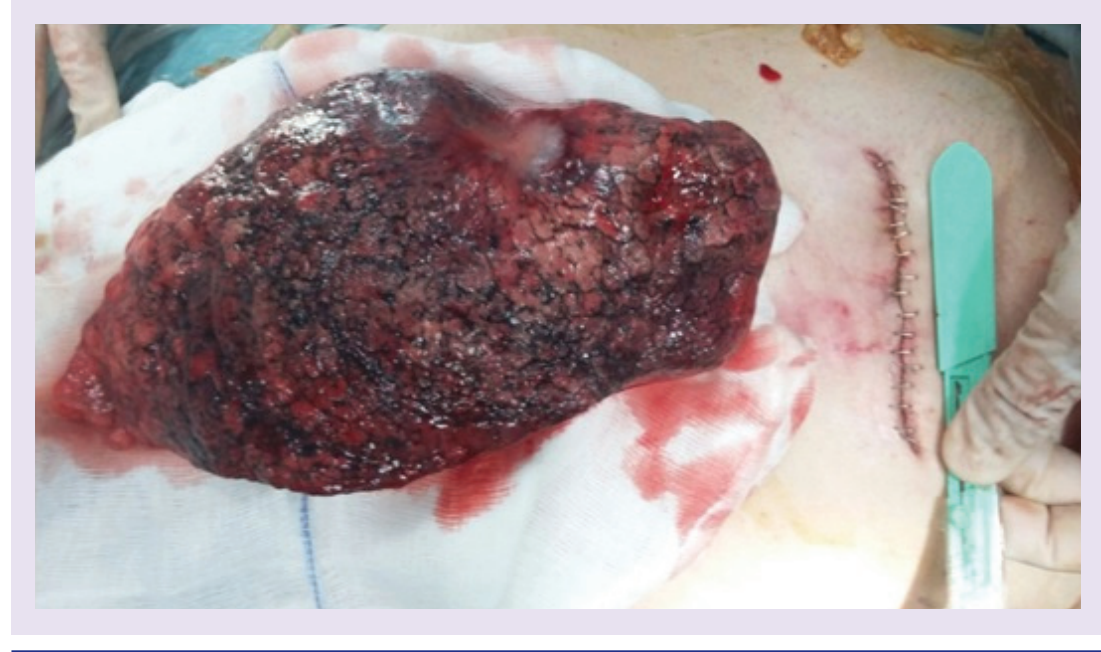

Figure 1. Video-assisted thoracic surgery left upper lobectomy. A biportal $6-\mathrm{cm}$ incision was used, but the left upper lobe was too big and the incision was enlarged to $8 \mathrm{~cm}$. inserted through a skin incision of no more than $2.0 \mathrm{~cm}$.

However, what is the meaning of port nowadays? Does the term 'port' still specify the same approach as in the past? It seems that today 'port' may be more liberally interpreted as a 'small open entry' waiving or avoiding any port or trocar. In other words: a single-incision VATS.

\section{Single-incision VATS}

Looking elsewhere, abdominal surgeons universally accepted the definition of single-incision laparoscopic surgery. We believe, single-incision VATS is the mirror definition of the technique in laparoscopic operation. In thoracic surgery, the term was used for the first time in 1998 to describe an operation to perform wedge resections of the lung for pneumothorax [10]. Recent papers have shown that the length of the skin incision to perform uniportal VATS lobectomy ranges from 2.5 to $5 \mathrm{~cm}$ [8,11-13]. Figure 2 pragmatically shows the difference between the definition of uniportal and single-incision VATS.

\section{Conclusion}

Uniportal (single-port) or single-incision VATS approaches have a common denominator which is the concept of using a rigid 0 or $30^{\circ}$ optic through a small opening or port (trocar) parallel to two or three instruments such as suction/irrigator device, electrocautery, endoscopic grasper or scissors, endoscopic ligaclips or open surgical instruments. Another important aspect thoracic operations performed through one port

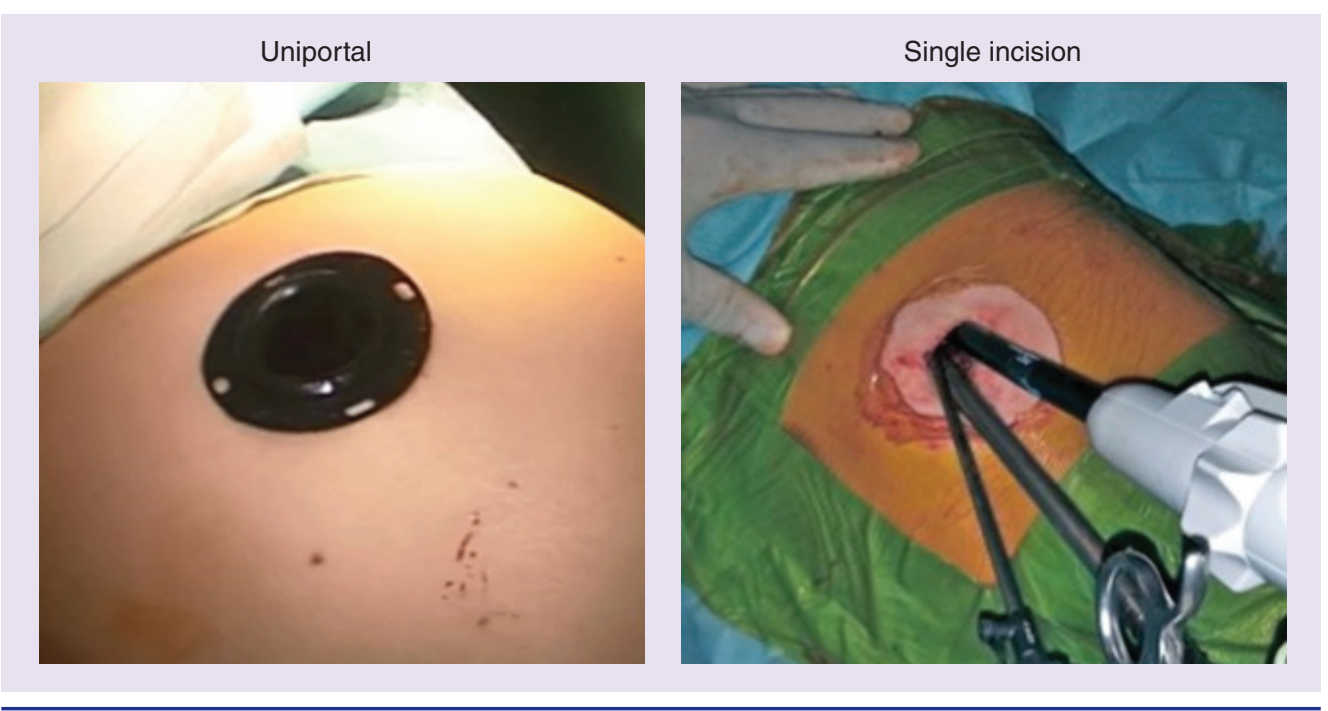

Figure 2. Pragmatic difference between uniportal and single-incision video-assisted thoracic surgery.

Reproduced with permission from S Halazeroglu. 
they have in common is that only one intercostal space is entered, and a single chest drain is inserted through the same skin incision. During bi-portal or three-portal VATS, a wound protector/retractor is also mandatory during uniportal or single-incision VATS to maximize surgical assistance, reduce the risk of wound infection and facilitates specimen removal.

In conclusion, we have attempted to resolve the existing ambiguity in VATS procedures, and propose specific terms identifying distinct approaches for minimally invasive thoracic procedures. A consensus conference between members of major thoracic societies such as European Society of Thoracic Surgeons, European Association of Cardio-thoracic Surgery, Society of Thoracic Surgeons, American Association of Thoracic Surgeons and Asian Society of cardiovascual and thoracic surgery will be probably necessary to make international nomenclature uniform.

\section{Financial \& competing interests disclosure}

The authors have no relevant affiliations or financial involvement with any organization or entity with a financial interest in or financial conflict with the subject matter or materials discussed in the manuscript. This includes employment, consultancies, honoraria, stock ownership or options, expert testimony, grants or patents received or pending or royalties.

No writing assistance was utilized in the production of this manuscript.

\section{References}

1 Treasure T. Videothoracoscopic resection for lung cancer: moving towards a "standard of care”. J. Thorac. Dis. 8, 8 (2016).

2 Tsunezuka Y, Oda M, Moriyama H. Would retraction system for lung resection by video-assisted mini-thoracotomy. Eur. J. Cardiothorac. Surg. 29(1), 110-111 (2006).

3 Migliore M, Deodato G. Thoracoscopic surgery, video-thoracoscopic surgery, or VATS: a confusion in definition. Ann. Thorac Surg. 69(6), 1990-1991 (2000).

4 Migliore M, Giuliano R, Deodato G. Video assisted thoracic surgery through a single port. Thoracic Surgery and Interdisciplinary Symposium on the threshold of the Third Millennium. An International Continuing Medical Education Programme. 29-30. Congress Centre - Continental Hotel,
Naples, Italy, 11-13 May 2000. http://xoomer.virgilio.it

5 Migliore M. Efficacy and safety of singletrocar technique for minimally invasive surgery of the chest in the treatment of noncomplex pleural disease. J. Thorac. Cardiovasc. Surg. 126, 1618-1623 (2003).

6 Migliore M, Deodato G. A single-trocar technique for minimally invasive surgery of the chest. Surg. Endosc. 15(8), 899-901 (2001).

7 Rocco G, Martin-Ucar A, Passera E. Uniportal VATS wedge pulmonary resections. Ann. Thorac. Surg. 77(2), 726-728 (2004).

8 Gonzalez D, Paradela M, Garcia J et al. Single-port video-assisted thoracoscopic lobectomy. Interact. Cardiovasc. Thorac. Surg. 12, 514-515 (2011).

9 Migliore M, Calvo D, Criscione A, Borrata F. Uniportal video assisted thoracic surgery: summary of experience, mini-review and perspectives. J. Thorac. Dis. 7(9), E378-E380 (2015).

10 YamamotoH, OkadaM, TakadaM et al. Video-assistedthoracic surgery through a single skin incision. Arch. Surg. 133, 145-147 (1998).

11 Kamiyoshihara M, Igai H, Ibe $\mathrm{T}$ et al. A 3.5-cm single-incision VATS anatomical segmentectomy for lung cancer. Ann. Thorac. Cardiovasc. Surg. 21, 178-182 (2015).

12 Ocakcioglu I, Sayir F, Dinc M. A 3-cm single-port video-assisted thoracoscopic lobectomy for lung cancer. Surg. Laparosc. Endosc. Percutan. Tech. 25, 351-353 (2015).

13 Yang HC, Noh D. Single incision thoracoscopic lobectomy through a $2.5 \mathrm{~cm}$ skin incision. J. Thorac. Dis. 7, E122-E115 (2015). 